\title{
İntra-abdominal apselerde görüntüleme yöntemleri rehberliğinde kateterle perkütan drenaj
}

\author{
Percutaneous drainage with a catheter in intra-abdominal abscesses under the guidance of imaging \\ methods \\ Muhammet Arslan, Halil Serdar Aslan, Furkan Ufuk, Muhammed Tekinhatun, Muhammed Efe, \\ Mustafa Ay, Gözde Songut, Tuğba Sarı
}

Gönderilme tarihi:12.10.2020

Kabul tarihi:23.11.2020

\section{Öz}

Amaç: İntra-abdominal apselere görüntüleme eşliğinde yaptığımız perkütan drenaj işlemlerinin etkinliğini, işlemlerin hangi kılavuz yöntemle yapııdığını, komplikasyonlarını, alınan örneklerden gelen kültür antibiyogram sonuçlarını ve hastalarımızın klinik sonuçlarını değerlendirmektir.

Gereç ve yöntem: Çalışmamız tek merkezli, retrospektif bir kohort çalışmasıdır. 01/06/2017-01/06/2019 tarihleri arasında hastanemiz girişimsel radyoloji bölümünde perkütan drenaj tedavisi uygulanan hastaların elektronik tıbbi kayıtları incelendi. Hastaların yaşı, cinsiyeti, işlemin yapılma yöntemi, kılavuz için kullanılan modalite, kullanılan kateter, oluşan komplikasyonlar, kateterin kaç gün kaldığı, hastaların kültür antibiyogram sonuçları araştırıldı.

Bulgular: Perkütan drenaj ile kateter yerleştirirken 187 işlemde Seldinger tekniği, 6 işlemde Trokar yöntemi uygulandığı görüldü. Kateter mal pozisyonu, kateter tıkanması, apsenin tekrarlaması, drenajın yeterli olmaması gibi nedenlerle perkütan drenaj yapılan apselerden 89 (\%5) tanesine ikinci bir işlem yapmak gerekti ve tekrarlayan kateter drenajı yapılan hastaların $75^{\prime} \mathrm{i}(\% 42)$ tedaviden sonra iyileşti. İntra-abdominal apselerde uygulanan perkütan drenaj tedavisinde toplamda başarı oranımız $\% 84,9$ olarak hesaplandı.

Sonuç: İntra-abdominal apselerde apse ile ilişkili intra-abdominal patoloji bulunmuyorsa perkütan drenaj işlemi tedavide ilk seçenek olarak değerlendirilmektedir. Perkütan drenaj işleminin erken dönem komplikasyonları yok denecek kadar az olup güvenli ve etkili bir tedavi yöntemidir. Hangi apselere sadece antibiyotik tedavisi verilmesi gerektiği, hangilerine ince iğneyle aspirasyonun yapılacağı, hangilerine drenaj kateteri yerleştirilmesi gerektiği, hangilerine açık cerrahi tedavi gerektiğine dair çalışmalar yapılmasına intiyaç vardır.

Anahtar kelimeler: Perkütan drenaj, apse, mikrobiyoloji, batın içi.

Arslan M, Aslan HS, Ufuk F, Tekinhatun M, Efe M, Ay M, Songut G, Sarı T. Intra-abdominal apselerde görüntüleme yöntemleri rehberliğinde kateterle perkütan drenaj. Pam Tıp Derg 2021;14:522-528.

\begin{abstract}
Purpose: Evaluation of the effectiveness of percutaneous drainage methods for intraabdominal abscesses, guiding method of the procedures, the complications, the culture antibiogram results from the samples taken, and the clinical results of our patients.

Materials and methods: Our study is a single-center, retrospective cohort study. Electronic medical records of patients undergoing percutaneous drainage treatment in our hospital interventional radiology department between 01/06/2017-01/06/2019 were examined. The age and gender of the patients, the method of performing the procedure, the modality used for the guideline, the catheter used, the complications that occurred, the number of days the catheter was left, and the culture antibiogram results of the patients were investigated.
\end{abstract}

Muhammet Arslan, Doç. Dr. Pamukkale Üniversitesi Tıp Fakültesi, Radyoloji Anabilim Dalı, Denizli, Türkiye, e-posta: dr.marslan@hotmail.com (https://orcid.org/0000-0001-5565-0770) (Sorumlu Yazar)

Halil Serdar Aslan, Dr. Öğr. Üye. Pamukkale Üniversitesi Tıp Fakültesi, Radyoloji Anabilim Dalı, Denizli, Türkiye, e-posta: draslan@outlook.com (https://orcid.org/0000-0002-5255-8618)

Furkan Ufuk, Doç. Dr. Pamukkale Üniversitesi Tıp Fakültesi, Radyoloji Anabilim Dalı, Denizli, Türkiye, e-posta: furkan.ufuk@hotmail.com (https://orcid.org/0000-0002-8614-5387)

Muhammed Tekinhatun, Uzm. Dr. Diyarbakır Bismil Devlet Hastanesi, Radyoloji Bölümü, Diyarbakır, Türkiye, e-posta: mtekinhatun@gmail.com (https://orcid.org/0000-0002-3240-6991)

Muhammed Efe, Öğrenci, Pamukkale Üniversitesi Tıp Fakültesi Öğrencisi, Denizli, Türkiye, e-posta: efe-0712320@hotmail.com (https://orcid. org/0000-0002-9291-0508)

Mustafa Ay, Öğrenci, Pamukkale Üniversitesi Tıp Fakültesi Öğrencisi, Denizli, Türkiye, e-posta: aymstfa7@gmail.com (https://orcid.org/00000002-7960-6990)

Gözde Songut, Öğrenci, Pamukkale Üniversitesi Tıp Fakültesi Öğrencisi, Denizli, Türkiye, e-posta: gozdeesongut@gmail.com (https://orcid. org/0000-0003-1458-2294)

Tuğba Sarı, Doç. Dr. Pamukkale Üniversitesi Tıp Fakültesi, Enfeksiyon Hastalıkları Anabilim Dalı, Denizli, Türkiye, e-posta: drtugba82@gmail. com (https://orcid.org/0000-0003-3204-2371) 
Results: It was observed that 187 of the catheter placement procedures with percutaneous drainage were applied Seldinger technique and 6 of them Trocar method. Due to reasons such as catheter malposition, catheter occlusion, recurrence of the abscess, insufficient drainage, $89(50 \%)$ of the abscesses with percutaneous drainage were required to perform a second procedure, and $75(42 \%)$ of the patients who underwent recurrent catheter drainage recovered after the treatment. Our overall success rate in percutaneous drainage treatment for intra-abdominal abscesses was calculated as $84.9 \%$.

Conclusion: For intra-abdominal abscesses, if there is no intra-abdominal pathology associated with abscess, percutaneous drainage procedure is considered as the first choice in treatment. Early period complications of percutaneous drainage are almost none and it is a safe and effective treatment method. Studies need to be carried out on which abscesses should only be treated with antibiotics, which ones should be aspirated with a fine needle, which ones should be placed with a drainage catheter, and which ones require open surgical treatment.

Key words: Percutaneous drainage, abscess, microbiology, intra-abdominal.

Arslan M, Aslan HS, Ufuk F, Tekinhatun M, Efe M, Ay M, Songut G, Sarı T. Percutaneous drainage with a catheter in intra-abdominal abscesses under the guidance of imaging methods. Pam Med J 2021;14:522-528.

\section{Giriş}

İntra-abdominal apse (IAA) karın boşluğu içerisinde yerleşmiş, fokal olarak sınırlanmış, süpüratif inflamatuar materyalden oluşan kistik koleksiyonlardır. İA'lar intraperitoneal, retroperitoneal ya da visseral yerleşimli olabilir. Apseyi kontrol altına almak için etkili bir antibiyoterapi başlanmalı ve uygun hastalarda apselerin içeriği boşaltılmalıdır [1]. Bu apselerin boşaltılmasında perkütan drenaj (PD) veya cerrahi yöntemler kullanılır. Perkütan drenaj daha kısa hastanede kalma süresi ve genel anestezi gerektirmeden yapılabildiği için ilk tercih edilen seçenektir [2]. PD sadece apse drenajı sağlanmamakta aynı zamanda sıvı içerisinden örnek alınması sağlanarak etken mikroorganizma tespit edilebilmektedir. Bu sayede mikroorganizmaya yönelik antibiyotik duyarlılık testlerinin çalışılması ile etkene yönelik spesifik tedavi başlanmasına olanak sağlamaktadır.

Çalışmamızın amacı; merkezimizde IAA nedeniyle görüntüleme eşliğinde yapılan PD işlemlerinin etkinliğini, işlem komplikasyonlarını, alınan örneklerden gelen kültür ve antibiyotik duyarlılık testi sonuçlarını ve hastalarımızın klinik sonuçlarını retrospektif olarak değerlendirmektir.

\section{Gereç ve yöntem}

Çalışmamız tek merkezli, retrospektif bir kohort çalışmasıdır. Pamukkale Üniversitesi Girişimsel Olmayan Klinik Araştırmalar Etik Kurulu'ndan onay alındıktan sonra 01/06/201701/06/2019 tarihleri arasında hastanemiz girişimsel radyoloji bölümünde $\mathrm{PD}$ tedavisi uygulanan hastaların elektronik tıbbi kayıtları incelendi. On sekiz yaşından küçük hastalar, apse drenajında kateter kullanılmayanlar ve batın dışı apse nedeniyle drenaj yaptığımız hastalar çalışmadan çıkarıldı. Aynı hastanın aynı apsesine ikinci veya üçüncü kez yaptığımız işlemler de çalışmadan çıkarıldı. Çalışma koşullarını sağlayan IAA nedeniyle PD yapılan toplam 178 hasta çalışmaya dahil edildi. Bu hastaların demografik özellikleri, hastalara hangi görüntüleme yöntemi eşliğinde $P D$ yapıldığı, işlem sırasında komplikasyon varlığı, apselerin hacmi ve lokalizasyonu, drenaj için hangi boyutta kateterin kullanıldığı, alınan örnekten gelen kültür ve antibiyogram sonuçları incelendi. Apselerin hacmi ve lokalizasyonları BT görüntüleri üzerinden değerlendirilerek çalışma cetveline not edildi. Bakteriyolojik tanı kanlı agarda ve EMB agarda bir gece $37^{\circ} \mathrm{C}$ 'de inkübe edilerek hazırlanan örneklerde $\geq 10^{5} \mathrm{cfu} /$ $\mathrm{ml}$ bakteriyel üreme olması halinde konuldu. İolatlar, konvansiyonel yöntemlerle tanımlandı ve antibiyotik duyarlılıkları EUCAST (European Committee on Antimicrobial Susceptibility Testing) kriterlerine uygun olarak disk difüzyon yöntemi ile araştırıldı. Hasta takibinde kateterin hastada ne kadar kaldığı, hastanın kaç gün hastanede yattığı da incelendi.

PD işlemi öncesi tüm hastaların görüntüleme bulguları değerlendirilip, uygun giriş yolu, kılavuz modalite önceden seçildi. Tüm PD işlemleri görüntüleme yöntemleri kılavuzluğunda, standart steril şartlarda gerçekleştirildi. Sadece bir hastada anksiyete nedeniyle bilinçli sedasyon uygulanırken diğer hastaların tümünde lokal anestezi ile işlem gerçekleştirildi. Apseye giriş Seldinger veya Trokar yöntemiyle 
yapıldı. Seldinger Tekniği'nde 18-gauge Chiba iğnesiyle apse içerisine girilerek lümene 0,035 inch sert bir kılavuz tel (Amplatz Super Stiff, Boston Scientific, Heredia, Costa Rica) ilerletildi. Uygun trakt dilatasyonu sonrasında tel üzerinden apse içerisine 8-14 French çaplı kilitli çok amaçlı drenaj kateteri (Flexima Locking Pigtail, Heredia, Costa Rica) yerleştirildi. Trokar yönteminde ise tel kullanılmayarak ciltteki küçük insizyondan kateter direkt olarak apsenin içine yerleştirildi. Kateter cilde tespit edildikten sonra ucuna drenaj torbası bağlanarak işleme son verildi. Yoğun içerikli olduğunu düşündüğümüz apselere ilk 7 gün günde 4 defa 20 mL SF (Serum fizyolojik) ile yıkama önerildi. Apselerden günlük gelen miktarlar takip edildi ve 20 mL'nin altına düştüğü tespit edilenler ultrasonografi (US) veya bilgisayarlı tomografi (BT) ile incelendi. Malpoze olan kateterler tekrar uygun yerlerine yerleştirildi. Kataterin yerinde olup apsesi küçülmüş olanlarda klinik ve laboratuvar düzelmesi de varsa kateterlerinin çekilmesine karar verildi.

Veriler SPSS 22.0 paket programı kullanılarak analiz edildi. Hastaların yaşı, cinsiyeti, işlemin yapılma yöntemi, kılavuz için kullanılan görüntüleme yöntemi, kullanılan kateter, komplikasyon varlığı, drenaj kateterinin kalış süresi, hastaların kültür antibiyogram sonuçları araştırıldı. Sürekli veriler ortalama ve standart sapma veya ortanca ve aralık olarak ifade edildi. Kategorik veriler ise yüzde (\%) olarak ifade edildi. İstatistiksel olarak $p$ değerinin 0,05’ten küçük olması anlamlı kabul edildi.

\section{Bulgular}

Abdominal bölgede apsesi olup PD tedavisi uygulanan 178 hastaya ait 193 apseye kateter yerleştirildiği tespit edildi. Toplam 15 hastaya birbiriyle ilişkisi olmayan birden fazla apsesi olması veya büyük boyutlu apse nedeniyle birden fazla drenaj kateteri yerleştirildi. Hastalarımızın 100'ü $(\% 56,2)$ erkek, 78'i $(\% 43,8)$ kadındı. Hastalarımızın yaşları 18 ile 91 arasında olup yaş ortalaması 57 olarak hesaplandı.

PD ile kateter yerleştirirken 187 işlemde Seldinger yöntemi, 6 işlemde ise Trokar yöntemi kullanıldığı görüldü. İşlemlerin çoğunluğunun sadece ultrasonografi (US) kılavuzluğunda (141 hasta), 34 hastanın işleminin US ve skopi eşliğinde, sadece 3 hastanın işleminin ise bilgisayarlı tomografi (BT) kılavuzluğunda yapıldığı tespit edildi. İşlem sırasında ağrı ve geçici bakteriyemi haricinde komplikasyon saptanmadı. 133 işlemde 8 french $(F), 48$ işlemde $10 \mathrm{~F}, 12$ işlemde ise 12 $F$ çapında kateter kullanıldığı görüldü. Kateter mal pozisyonu, kateter tıkanması, apsenin tekrarlaması, drenajın yeterli olmaması gibi nedenlerle perkütan drenaj yapılan apselerden 89 (\%50) tanesine ikinci bir işlem yapıldı. İkinci işlem genellikle yeniden perkütan drenaj işlemi iken bazı hastalar cerrahi tedavi açısından değerlendirilmek üzere genel cerrahi bölümüne yönlendirildi. Tekrarlayan kateter drenajı yaptığımız hastaların 75’i (\%42) tedaviden fayda görerek iyileşti. Bununla birlikte apse tedavisinde perkütan drenajla toplamda başarı oranımız \%84,9 olarak hesaplandı. Batın duvarı ve dalak apselerinin tamamı perkütan drenaj ile tedavi edilebildi. Peripankreatik bölge apselerinin yarısı (6 apse) perkütan drenaj kateterinden yeterli fayda göremedi. Sol üst kadran ve sağ üst kadran apselerinden beşer tanesi, karaciğer ve sol alt kadran apselerinden dörder tanesi, sağ alt kadran apselerinden 3 apse, psoas ve böbrek apselerinden birer apse kateter işleminden yeteri kadar fayda göremedi ve cerrahi tedavi açısından genel cerrahiye danışıldı.

Kateter için iğneyle apse içerisine giriş yapıldığında tüm hastalardan mikrobiyolojiye örnek gönderildi. Apse poş kültür sonucunda 98 (\%55) kişide etken mikroorganizma saptanırken, 80 kişiden alınan örneklerde mikroorganizma üremesi olmadı. En çok saptanan mikroorganizma Escherichia coli olarak tespit edildi (Tablo 1).

Hastalara takılan ilk kateterin kalma süresi 1-60 gün arasında ortalama 13,27 (standart sapma: 11,07) gün olarak hesaplanmıştır (kadınlarda ort: 13,29 gün, erkeklerde ort: 13,25 gün). Ancak aynı apseye tekrarlayan girişimlerle 178 güne kadar uzayan kateter kalma süreleri bulundu. Hastalarımızdaki apselerin işlem öncesi hacmi 8,8-3575 $\mathrm{mL}$ aralığında ve ortalaması ise $328,18 \mathrm{~mL}$ idi. 175 apse 8,8 ile $1000 \mathrm{~mL}$ apse hacmine, 15 apse $1000-2000 \mathrm{~mL}$ apse hacmine ve 2 apse $2000-3000 \mathrm{~mL}$ apse hacmine sahipti. Sadece bir apse 3000 mL'den büyük apse hacmine sahipti. En küçük apsenin uzun aksı 3,2 cm, en büyük apsenin uzun aksı ise $24 \mathrm{~cm}$ idi. Hastalarımızda apse en çok sağ alt kadranda yer almaktaydı. Apse lokalizasyonları Şekil 1'de sunulmuştur. 
Tablo 1. Apse poş kültüründen üretilen mikroorganizmalar

\begin{tabular}{ll}
\hline Mikroorganizmalar & Sayı/yüzde \\
\hline Escherichiacoli & $26 / 26,5$ \\
Klebsiellapneumonia & $10 / 10$ \\
Pseudomonasaeruginosa & $10 / 10$ \\
Enterococcus & $7 / 7$ \\
Staphylococcus & $6 / 6$ \\
Anaeroblar & $6 / 6$ \\
Mantarlar & $4 / 4$ \\
Proteus & $2 / 2$ \\
Streptococcus & $2 / 2$ \\
Mycobacteriumtuberculosis & $1 / 1$ \\
Polimikrobiyal & $24 / 24,5$ \\
\hline
\end{tabular}

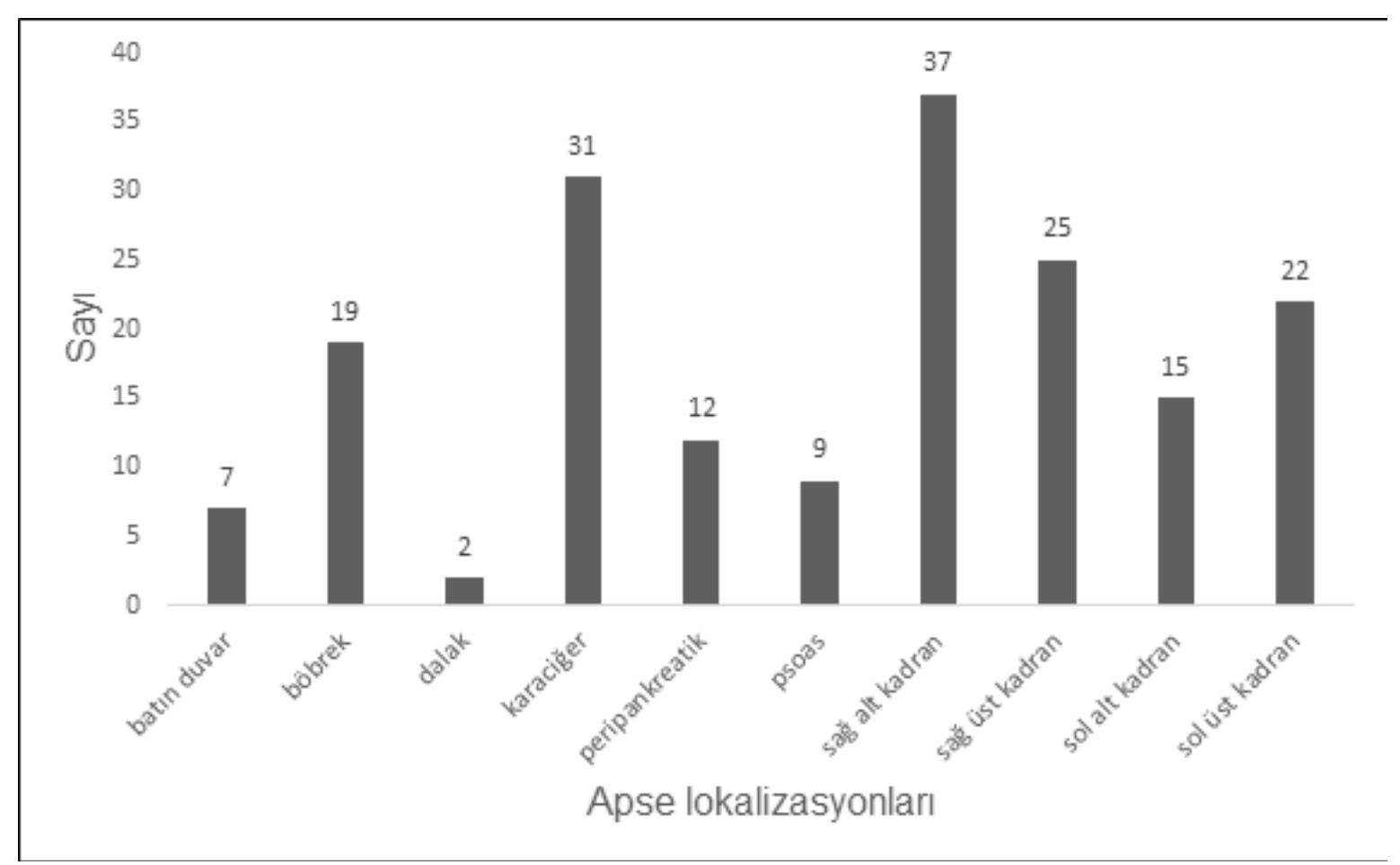

Şekil 1. Apse lokalizasyonlarının dağııımı 


\section{Tartışma}

Günümüzde İA'ların ilk tercih edilen tedavisi antibiyotik ile birlikte perkütan tedaviler olmuştur [3-5].Cerrahi drenajlar daha yüksek mortalite ve morbiditeye sahip olduğundan ikinci seçenek olarak kullanılmalıdır [5]. Sadece apse ile ilişkili intra-abdominal patolojilerin varlığında cerrahi tedavi daha önemlidir [6]. Çalışmamızda ilk apse drenajı sonrası hastalarımızın \%50'sinin iyileştiği görüldü. Bu oran literatürle kıyaslandığında biraz düşüktür. Akıncı ve ark.'nın [7] 300 hasta üzerinden yaptıkları çalışmada ilk perkütan drenaj sonrası tedavi başarısını \%68 olarak bulmuşlardır. Bu çalışmada sadece kateter yerleştirilen değil iğne ile aspire edilen apseler de çalışmaya dahil edilmiştir. İlk kateterizasyonda tedavi başarımızın daha düşük olmasının nedenini sadece kateter yerleştirdiğimiz büyük boyutlu apseleri çalışmamıza almamız olduğunu düşünüyoruz; ancak tekrarlayan girişimler ile hastalarımızın \%84,9'nun intra-abdominal apseleri iyileşmiştir. Bu oran da literatürde belirtilen \%70-100 başarı ile uyumludur [7, 8].

Görüntüleme yöntemi eşliğinde yapılan PD işlemi öncesi tüm hastaların görüntüleme sonuçları değerlendirilip, uygun giriş yolu, kılavuz modalite önceden seçildiğinden ve IAA'lardan sadece PD'ye uygun olanlar işleme alındığından, işlemin teknik başarısı oldukça yüksektir. Bizim çalışmamıza PD işlemi yapılanlar dahil edildiğinden teknik başarımızı bilemiyoruz. Yine işlemin görüntüleme kılavuzluğunda yapılması sayesinde işleme bağlı büyük komplikasyon görülmesi çok nadir olup biz de işlemlerimizde erken dönemde büyük komplikasyona rastlamadık. Tekrar kateter yerleştirme nedenlerimiz arasında en sık olarak kateter mal pozisyonu ve kateter tıkanması yer alıyordu. Kateterin erken çekilmesi de tekrar kateter yerleştirilmesine neden olabilmektedir. Bu nedenle günlük gelen miktarı 20 mL'nin altına düşse dahi apsenin durumunu görüntüleme yöntemlerinden biriyle değerlendirilmesi tekrar eden girişimleri önleyecektir [9]. Ayrıca apse içeriğinin yoğun olması da drenajı zorlaştırıp hastanın cerrahi drenaja gitmesine sebep olan faktörlerdendir. Kateterli drenaja rağmen iyileşmeyen hastalarımızın bir kısmında (3 hasta, \%1,5) da gastrointestinal sistem fistülleri mevcuttu.
Kateterin hastada kalma süreleri morbiditeyi arttıran unsurlardan olup evde bakım hizmeti alabilenleri sadece kateter nedeniyle hospitalize etmek gereksizdir. Hastada kateterin kalma süresi literatürde 2 ile 120 gün arasında değişmekte olup ortalama kalma süresi ise 13 gündür [7]. Bizim çalışmamızda literatür ile uyumlu olup 13,4 gün olarak hesaplanmıştır.

İntra-abdominal apselerden $3 \mathrm{~cm}$ çapın altında olanların sadece antibiyotik ile tedavi edilmesi önerilmektedir [10]. Daha büyük apselerde ise drenaj önerilmekte olup hangilerine sadece aspirasyon, hangilerine kateter ile drenaj yapılacağına yönelik henüz tam bir fikir birliği yoktur. Genel olarak $4,5 \mathrm{~cm}$ ve üstündeki lezyonlara kateter ile drenaj önerilmektedir [11]. Çalışmamıza kateter taktığımız hastaları dahil ettiğimiz için apse boyutlarımız nispeten büyüktü. En küçük apse boyutumuz 3,2 cm olup en küçük apse hacmi ise $8 \mathrm{~mL}$ olarak ölçüldü. Apselerimizin ortalama hacmi $328 \mathrm{~mL}$ olup $1000 \mathrm{~mL}$ den büyük boyutlu 18 tane apsemiz vardı. Dev boyutlu bu apselere daha geniş çaplı drenaj kateteri veya aynı apseye birden fazla kateter takılabilir.

IAA'lar intraperitoneal, retroperitoneal ve visseral olarak sınıflandırılabilir. Biz çalışmamızda anatomik kadran sınıflamasını ve visseral organlara göre sınıflandırmayı tercih ettik. Apse lokalizasyonları daha çok önceden geçirilmiş cerrahi operasyon ile ilişkilidir [8]. Diyabetes mellitus ve malignite geçirilmiş cerrahiden sonra en sık rastlanan etiyolojik nedenlerdendir [1]. Çalışmamızda en sık sağ alt kadranda apse ile karşılaştık ve bunun da nedeninin perfore apandisite bağlı olabileceğini düşünmekteyiz.

Perkütan apse drenajı apse içindeki ölü dokuları ve lökositlerden oluşan materyali tahliye ederken tedavi sağlamaktadır. Drenaj sırasında alınan örnekten kültür antibiyogram çalışılması ise antibiyotik tedavisini değiştirebilir ve tedavinin etkinliğini artırabilir. Biz tüm hastalardan örnek alarak kültür antibiyogram gönderdik bu numunelerin $\% 55$ 'inde mikroorganizma üremesi oldu. PD öncesi ampirik antibiyotik tedavisi başlanan hastalar poş kültürünün sonuç vermemesine etki edebilmektedir [12]. Çalışmamızda en çok üretilen mikroorganizma Escherichia coli olup literatür ile uyumlu bulundu [1]. Apse etiyolojisi ve lokalizasyonu ile mikroorganizma arasında 
doğrudan ilişki olduğu gösterilmiştir [1]. Ancak çalışmamızda apse etiyolojini araştırmak amaçlarımız arasında olmadığından bu ilişkiyi değerlendirmedik.

Çalışmamızın bazı sınırıııkları mevcuttur. Çalışmamız retrospektif olması nedeniyle veriler hasta kayıtlarından toplanmıştır. Bir diğer sınırlılık ise çalışmamıza apsenin diğer tedavi yöntemlerini dahil etmedik. Bu nedenle cerrahi tedavi gibi yöntemlerle PD etkinliğini karşılaştıramadık. Hasta notlarından işlem sonrası geç dönem komplikasyonların kayıtlarına ulaşamadığımız için sadece işlem esnasındaki komplikasyon varlığını inceleyebildik. Son olarak, hastalarımızda apseye neden olan etiyolojik nedenleri değerlendiremememiz, çalışmamızın amaçları dışında olsa da, bir sınırlılık olarak kabul edilebilir.

Sonuç olarak, IAA'da özellikle de apse ile ilişkili perforasyon veya fistül gibi intra-abdominal patoloji yoksa PD tedavi için ilk seçenek olarak değerlendirilmelidir. PD işleminin erken dönem komplikasyonları çok nadir olup güvenli ve etkili bir tedavi yöntemidir. Ayrıca kültür antibiyogram için örnek de alınabildiğinden, etkili antibi yotik tedavisi için büyük öneme sahiptir. Hangi apselere sadece antibiyotik tedavisi verilmesi gerektiği, hangilerine ince iğneyle aspirasyonun yapılacağı, hangilerine drenaj kateteri yerleştirilmesi gerektiği, hangilerine açık cerrahi tedavi gerektiğine dair çok merkezli randomize çalışmalara intiyaç vardır.

Çıkar ilişkisi: Yazarlar çıkar ilişkisi olmadığını beyan eder.

\section{Kaynaklar}

1. Akcam FZ, Ceylan T, Kaya O, Ceylan E, Tarhan OR. Etiology, treatment options and prognosis of abdominal abscesses: a tertiary hospital experience. J Infect Dev Ctries 2020;14:59-65. https://doi.org/10.3855/ jidc. 11277

2. Carbajo AY, Brunie Vegas FJ, García Alonso FJ, et al. Retrospective cohort study comparing endoscopic ultrasound-guided and percutaneous drainage of upper abdominal abscesses. Dig Endosc 2019;31:431438. https://doi.org/10.1111/den.13342

3. Cai YL, Xiong XZ, Lu J, et al. Percutaneous needle aspiration versus catheter drainage in the management of liver abscess: a systematic review and metaanalysis. HPB (Oxford) 2015;17:195-201. https://doi. org/10.1111/hpb.12332
4. Solomkin JS, Mazuski JE, Bradley JS, et al. Diagnosis and management of complicated intra-abdominal infection in adults and children: guidelines by the Surgical Infection Society and the Infectious Diseases Society of America. Clin Infect Dis 2010;50:133-164. https://doi.org/10.1086/649554

5. Politano AD, Hranjec T, Rosenberger LH, Sawyer RG, Tache Leon CA. Differences in morbidity and mortality with percutaneous versus open surgical drainage of postoperative intra-abdominal infections: a review of 686 cases. Am Surg 2011;77:862-867.

6. Malik AA, Bari SU, Rouf KA, Wani KA. Pyogenic liver abscess: changing patterns in approach. World J Gastrointest Surg 2010;2:395-401. https://doi. org/10.4240/wjgs.v2.i12.395

7. Akinci D, Akhan $\mathrm{O}$, Ozmen MN, et al. Percutaneous drainage of 300 intraperitoneal abscesses with long-term follow-up. Cardiovasc Intervent Radiol 2005;28,744-750. https://doi.org/10.1007/ s00270-004-0281-4

8. Damar Ç, Özdemir M, Hekimoğlu B. İntraabdominal apselerin görüntüleme eşliğinde perkütan drenajı. Dicle Tıp Dergisi 2019;46:73-83. https://doi.org/10.5798/ dicletip

9. Springer JE, Doumouras AG, Nair S, Eskicioglu C, Forbes S. Does imaging before percutaneous drain removal affect rates of intra-abdominal abscess recurrence? J Surg Res 2018;232:408-414. https://doi.org/10.1016/j.jss.2018.06.062

10. Cinquantini F, Piccinini A, Montanari N, Biscardi A, Tugnoli G, DiSaverio S. Percutaneous techniques for management of intra-abdominal abscesses. In: Di Saverio S, Catena F, Ansaloni L, Coccolini F, Velmahos G, eds. Acute Care Surgery Handbook. Springer, Cham 2017;371-385. https://doi.org/10.1007/978-3319-15341-4_21

11. Singh P, Tapasvi C, Kaur R, Aggarwal S, Nagpal $\mathrm{N}$, Kaur R. Prospective randomized comparison of ultrasound-guided percutaneous needle aspiration with percutaneous catheter drainage of liver abscesses. J Med Sci 2019;39:67-73. https://dx.doi.org/10.4103/ jmedsci.jmedsci_74_18

12. Serraino C, Elia C, Bracco C, et al. Characteristics and management of pyogenic liver abscess: a European experience. Medicine (Baltimore) 2018;97:628. https:// doi.org/10.1097/MD.0000000000010628

Etik kurul onayı: Çalışma için Pamukkale Üniversitesi Girişimsel Olmayan Klinik Araştırmalar Etik Kurulu'ndan 10.06.2020 tarih ve 34118 sayı ile onay alınmıştır. 


\section{Yazarların makaleye olan katkıları}

M.A., M.T., M.E., M.A. ve G.S. çalışmanın ana fikrini ve hipotezini kurgulamışlardır. M.A., M.E., M.A., G.S. ve H.S.A. teoriyi geliştirmiş ve gereç yöntem bölümünü düzenlemişlerdir. Sonuçlar kısmınındaki verilerin değerlendirmesini M.A.,
H.S.A., T.S., F.U., M.T., M.A., M.E. ve G.S. yapmışlardır. Makalenin tartışma bölümü M.A. ve H.S.A. tarafından yazılmış, F.U. ve T.S. gözden geçirip gerekli düzeltmeleri yapmış ve onaylamıştır. Ayrıca tüm yazarlar çalışmanın tamamını tartışmış ve son halini onaylamıştır. 